\title{
$\beta$-Adrenoceptor signaling networks in adipocytes for recruiting stored fat and energy expenditure
}

\section{Sheila Collins*}

Diabetes and Obesity Research Center, Sanford-Burnham Medical Research Institute, Orlando, FL, USA

\section{Edited by:}

Patrick Seale, University of

Pennsylvania, USA

\section{Reviewed by:}

Diego Perez-Tilve, University of

Cincinnati College of Medicine, USA Maria Christina Werneck Avellar,

Universidade Federal de Sao Paulo,

Brazil

Pascale Crepieux, Centre National de la Recherche Scientifique, France

\section{${ }^{*}$ Correspondence:}

Sheila Collins, Diabetes and Obesity Research Center, Sanford-Burnham

Medical Research Institute, 6400

Sanger Road, Orlando, FL 32827,

USA.

e-mail: scollins@sanfordburnham.org
The adipocyte is like a bank: a place to store excess (caloric) cash in times of plenty, and from which one can withdraw savings during "lean times." The $\beta$-adrenoceptors ( $\beta A R$ ) are the gateways to this mobilization of fat to be consumed in other tissues. This review discusses the $\beta A R$ signaling pathway(s) in white and brown adipocytes. Studies in rodent models show that brown adipocytes nestled with white fat depots correlate with and are considered a key enabling factor in resistance to diet-induced obesity. Since it is now recognized that adult humans have brown adipocytes, knowing the steps in these signaling pathways may provide the opportunity to manipulate adipocytes to be net consumers of energy.

Keywords: adrenergic, adipocyte, brown, white, signaling, kinase
The catecholamines adrenaline and noradrenaline are well known as the physiological trigger for hydrolyzing stored fat in adipose tissue so that it can be "burned" as fuel in other organs. Adrenaline is commonly referred to as the "fight or flight" hormone. This is because it orchestrates the body's defensive response for rapid recruitment of metabolic fuel from adipose tissue lipolysis, as well as to increase heart rate to enhance tissue perfusion so that organs such as skeletal muscle, and the heart itself, can extract, and metabolize that fuel. These catecholamines control fat cell metabolism in large part through activation of the $\beta$-adrenoceptors ( $\beta$ ARs). The $\beta$ ARs are members of the large family of $G$ protein-coupled receptors (GPCRs) that are integral membrane proteins of the plasma membrane. The three subtypes of $\beta$ ARs ( $\beta_{1} A R, \beta_{2} A R$, and $\beta_{3} A R$ ) are the products of different genes, and adipocytes express all three subtypes. In the mid-late 1980 s the discovery of the $\beta_{3}$ AR subtype and selective ligands for this receptor led to a period of intense interest in this receptor. This was largely because of the powerful effect of selective $\beta_{3} \mathrm{AR}$ agonists to promote energy expenditure and weight loss in animal models. However, the relatively poor preliminary performance of human $\beta_{3} \mathrm{AR}$ agonists in clinical trials (Buemann et al., 2000; Arch, 2002) - and the general belief that adult humans do not possess brown fat - led to the termination of most such research programs.

$\beta$-Adrenoceptor activation promotes lipolysis of stored triglyceride in both white and brown adipocytes. In brown adipocytes there is a dense sympathetic nervous system (SNS) innervation and these fatty acids that are released function as both a fuel source and activators of the UCP1 protein, which permits mitochondrial respiration without ATP generation (as discussed elsewhere in this edited volume). Because of this high capacity for uncoupled oxidative respiration, BAT is capable of consuming considerable calories through non-shivering thermogenesis (Lean, 1989; Nedergaard et al., 2001). Its rich vasculature allows the dissemination of this heat to other organs. From detailed studies in rodents we know that prolonged cold acclimation, which increases SNS activation of BAT (and WAT), induces the appearance of brown adipocytes in all adipose depots typically considered to be WAT. Brown adipocytes can be found within several typical WAT depots including cervical, axillary, perirenal, periadrenal, and pericardiac depots (Kortelainen et al., 1993; Cinti, 2005). The increase in these cells involves branching and increased activity of the sympathetic nerve fibers within both BAT and WAT (Garofalo et al., 1996; Giordano et al., 1996; De Matteis et al., 1998; Cinti, 1999, 2005). The essential role of the SNS in promoting the increased number and activity of these brown adipocytes is supported by data from mice deficient in the synthesis of noradrenaline or in BARs themselves (Thomas and Palmiter, 1997; Bachman et al., 2002; Jimenez et al., 2002). In these mutants, there is an absence of BAT that is replaced by WAT, and they tend to be obese. A similar loss of functioning BAT is observed in animals that have been maintained at thermoneutrality, a state in which there is little to no SNS activity in fat (Cinti, 1999). All together, these results suggest that $\beta$-agonists have the potential to promote postnatal changes in the WAT/BAT ratio. This could have profound implications, for example, in inducing weight loss in humans as is already observed in laboratory animals such as rodents as well as in adult dogs and rhesus monkeys (Arch et al., 1984; Champigny et al., 1991; Cousin et al., 1992; Himms-Hagen et al., 1994; Collins et al., 1997; Fisher et al., 1998). The latter two species, like humans, do not appear to retain large discrete depots of BAT in adulthood. 


\section{SIGNAL TRANSDUCTION NETWORKS OF $\beta$ ARs IN ADIPOCYTES}

A basic biochemical scheme for the stimulation of adipocyte metabolism by $\beta A R$ s is presented in Figure 1. In both brown and white adipocytes activation of $\beta$ ARs sets in motion the classic signaling paradigm in which the receptor interacts with the heterotrimeric GTP-binding protein Gs that, in turn, activates adenylyl cyclase to raise intracellular cAMP levels, the target of which is the cAMP-dependent protein kinase (PKA). In adipocytes PKA phosphorylates several proteins that decorate the lipid droplet (Brasaemle et al., 2004; Brasaemle, 2007; Bickel et al., 2009) as well as lipases that catalyze the hydrolysis of triglycerides (Lass et al., 2011). The interaction of these phosphorylated proteins at the lipid droplet surface culminates in the release of free fatty acids and glycerol and their export into the circulation to be consumed as fuel in other tissues. However, signal transduction through GPCRs, including the $\beta A R s$, can consist of multi-component complexes capable of activating several kinase pathways either concurrently or sequentially (see Luttrell, 2003 and Reiter and Lefkowitz, 2006 for reviews).

PKA is a well-established downstream agent of the $\beta$ ARs. However, other kinases are also activated by $\beta$ ARs in adipocytes such as ERK, p38 MAP, and AMP kinases (Collins et al., 2004; Gauthier et al., 2008; Omar et al., 2009). The activation of these other kinase classes sometimes depends directly upon PKA, while for others a connection to PKA exists only as a consequence of its lipid mobilizing effects (Gauthier et al., 2008). In addition, PKA in adipocytes is largely Type II, denoting its relative sensitivity to ambient cAMP levels as compared to Type I (Corbin et al., 1975). In adipocytes PKA is also membrane-anchored through interaction with the A-kinase anchoring proteins (AKAPS; McConnachie

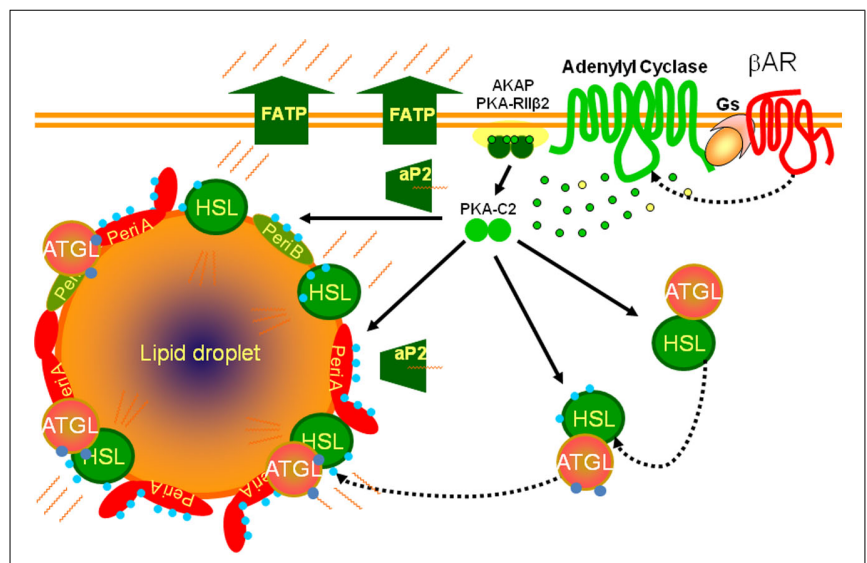

FIGURE 1 | Scheme for $\beta A R$ signaling cascades controlling lipolysis in adipocytes. $\beta A R s$ activate adenylyl cyclase through their coupling to the heterotrimeric Gs, producing cAMP (green dots) from ATP (yellow dots) to activate the cAMP-dependent protein kinase (PKA), allowing the catalytic subunits (PKA-C2) to be released from the holoenzyme that is anchored to the plasma membrane (AKAP). PKA phosphorylates (blue dots) lipases (HSL: hormone sensitive lipase) and lipid droplet binding proteins such as perilipins (Peri A; Peri B). Adipose triglyceride lipase (ATGL) is phosphorylated but not by PKA. The fatty acids released from triglyceride are chaperoned out of the cell by lipid binding proteins (aP2) and exported through fatty acid transport proteins (FATP). et al., 2006). Thus there are spatial aspects to PKA activation to consider as well. In that regard an interesting new report identifies optic atrophy-1 (OPA1), a protein best known for its role in mitochondrial "quality control", as an AKAP targeting PKA to the lipid droplet to facilitate perilipin phosphorylation and activation of lipolysis (Pidoux et al., 2011).

$\mathrm{G}$ protein-coupled receptors coupled to heterotrimeric $\mathrm{Gi}$ antagonize the activation of adenylyl cyclase in response to $\beta$ ARs. With the discovery that GPCRs coupled to Gi can also activate the ERK MAP kinase pathway (Daub et al., 1996; van Biesen et al., 1996), we now know that the picture is a bit more complex. Another dimension to this signaling is that GPCRs can, under certain circumstances, couple to more than one $G$ protein. This is relevant to $\beta A R$ signaling in adipocytes in that $\beta_{2} A R$ was shown to activate ERK following their phosphorylation by PKA. As shown in Figure 2, this phosphorylation diminishes $\beta_{2} \mathrm{AR}$ coupling to Gs and increases coupling to Gi (Zamah et al., 2002; Martin et al., 2004). Figure 2 also shows that this signaling pathway includes additional phosphorylation events by GPCR kinases (GRKs), which triggers the binding of $\beta$-arrestin (Lefkowitz et al., 2006): a scaffolding molecule first shown to be involved in the desensitization of $\beta_{2} \mathrm{AR}$ to terminate its activation of adenylyl cyclase (Lohse et al., 1990). Subsequently, Luttrell et al. (1999) showed that $\beta$-arrestin has broader roles; first showing that it could recruit Src kinase into a complex that leads to ERK activation through proline-rich regions that bind the $\mathrm{SH} 3$-domain of Src (see Figure 2).

Functionally this aspect of $\beta A R$ signaling is important for adipocytes because $\beta$ AR activation of ERK is responsible for about 20-25\% of lipolysis (Greenberg et al., 2001; Robidoux et al., 2006). $\beta_{3} \mathrm{AR}$ in particular is interesting in this regard because it can activate both PKA and ERK by interacting with Gs and Gi interchangeably in the absence of receptor phosphorylation

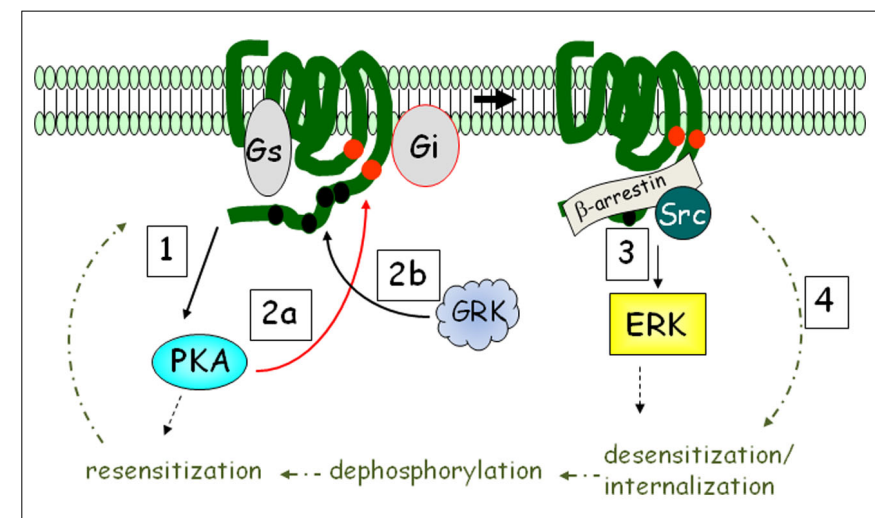

FIGURE 2 | $\beta$ ARs activate ERK MAPK in addition to PKA: the $\beta_{2} A R$ mechanism as an example. Upon catecholamine activation, PKA is activated (step 1), and phosphorylates the receptor at intracellular sites (red circles; step 2a). The receptor is also phosphorylated by $\mathrm{G}$ protein-coupled receptor kinase (GRK) at multiple sites in the C-terminus (step 2b). PKA phosphorylation interdicts interaction with $\mathrm{Gs}$ to favor $\mathrm{Gi}$, while GRK recruits $\beta$-arrestin, promoting ERK activation (step 3 ). $\beta_{2} A R$ is subject to rapid desensitization and internalization (step 4), whereupon phosphatases remove the phosphates and the receptor is recycled back to the plasma membrane. 
and $\beta$-arrestin (Liggett et al., 1993; Soeder et al., 1999). Instead, we identified a novel mechanism by which $\beta_{3} \mathrm{AR}$ is able to activate ERK. As illustrated in Figure $3 \mathbf{A}, \beta_{3} \mathrm{AR}$ contains clusters of proline motifs in the two most important intracellular regions of a GPCR: the third intracellular loop and the carboxyl terminus. These prolines are arranged in the PXXP motif that serves as agonist-dependent docking sites for the SH3-domain of Src. The ability of $\beta_{3} \mathrm{AR}$ to directly recruit Src kinase in adipocytes is shown in Figure 3B (adapted from Cao et al., 2000, and see legend). The $\beta_{3}$ AR-selective agonist CL316243 (CL), triggers ERK activation via the endogenous $\beta_{3} \mathrm{AR}$ in non-transfected (NT) cells, and in cells transfected with HA-tagged mouse $\beta_{3} \mathrm{AR}$. In the presence of pertussis toxin (PTX), ERK activation was abolished, indicating the requirement for signaling through the heterotrimeric Gi. Figure 3B shows that Src kinase co-precipitates with the HA- $\beta_{3} \mathrm{AR}$, and this interaction is both $\beta_{3}$-agonist and Gi-dependent. As shown further by Cao et al. there are three to four of these PXXP motifs within all the species homologs of $\beta_{3} \mathrm{AR}$, but perturbations of only one or two of these are enough to eliminate ERK activation (Cao et al., 2000; Kumar et al., 2007).

A

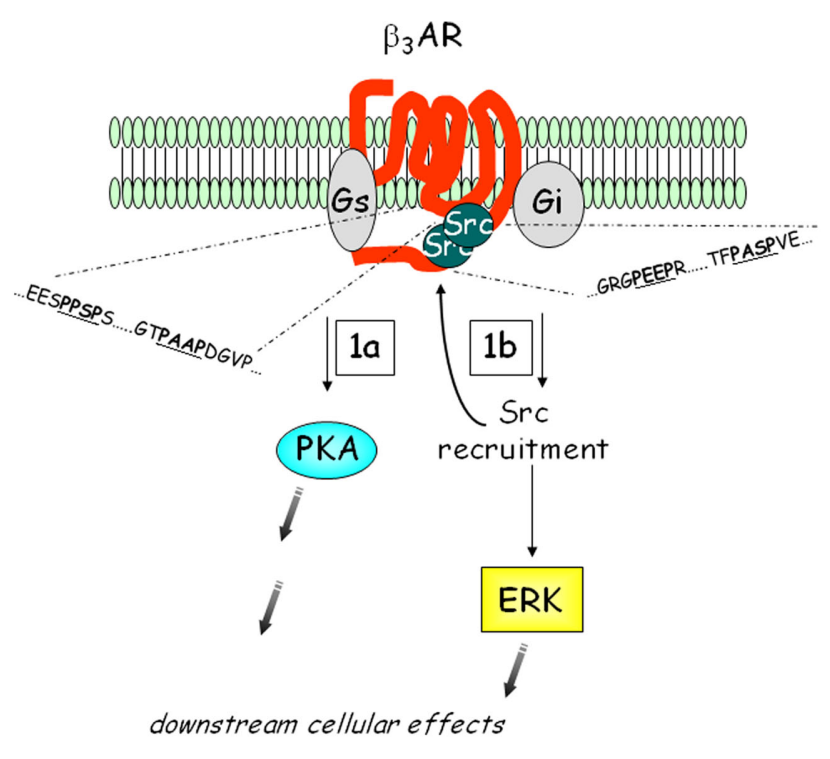

B

a Northern blot

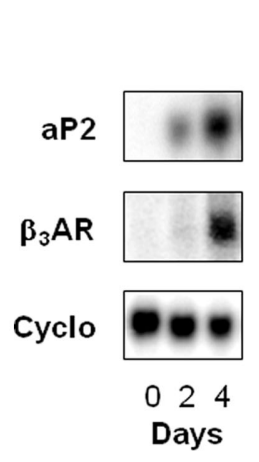

b Cell lysate
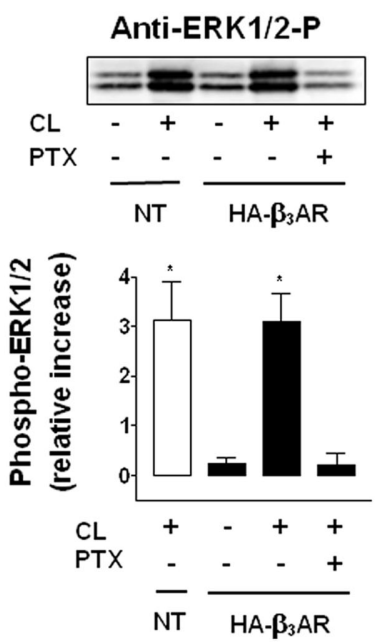

c IP
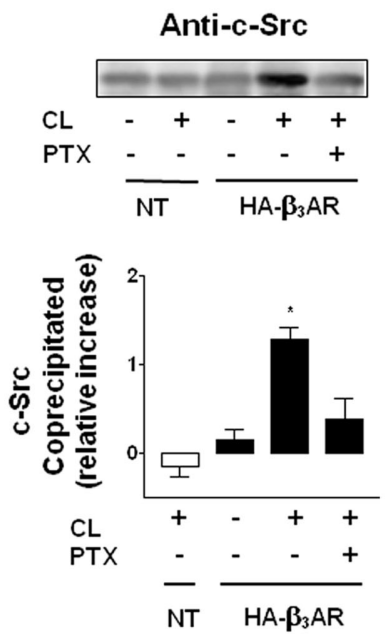

FIGURE 3 | A unique dual signaling mechanism by $\boldsymbol{\beta}_{3} \mathbf{A R}$. (A) The receptor can couple to both Gs and Gi to activate PKA (step 1a) and ERK (step 1b). The shaded gray arrows point to subsequent downstream cellular effects. (B) Preadipocytes were transfected or not (NT) with hemagglutinin (HA)-tagged $\beta_{3} A R$ and differentiated. (a) Expression of aP2 and $\beta_{3} A R$ mRNA as a function of differentiation on the indicated days. Levels of aP2 are maximal by day 4 . Cyclophilin RNA (Cyclo) is the internal control. (b) Phospho-ERK1/2 in cell lysates in response to the $\beta_{3} A R$ agonist CL316243 (CL) in the absence or presence of pertussis toxin (PTX; $n=3$; mean \pm SD). (c) Level of c-Src co-precipitated with $\beta_{3} \mathrm{AR}$ ( $n=3$; mean $\pm \mathrm{SD}$ ). (Adapted from Cao et al., 2000). 
These results suggested that there could perhaps be other molecules in addition to Src that might be recruited to the receptor as part of a larger complex. A proteomic search for proteins that could be co-immunoprecipitated with the $\beta_{3} \mathrm{AR}$ from adipocytes in an agonist-dependent manner identified several proteins that interact with the receptor and the proline motifs, among which was the intermediate filament protein vimentin (Kumar et al., 2007). Vimentin is a component of the lipid droplet in adipocytes (Franke et al., 1987), and was found to be required in adipocytes for both ERK activation and lipolysis (Kumar et al., 2007). Several aspects of this mechanism as well as its significance remain incomplete. These include (i) knowledge of the target(s) of ERK that are responsible for lipolysis; (ii) the mechanism by which vimentin is recruited to the $\beta_{3} \mathrm{AR}$, since it does not possess an $\mathrm{SH} 3$ binding domain, and therefore perhaps requires a protein intermediate; (iii) the relative importance of ERK in lipolysis in human adipocytes; (iv) what other events might be regulated by this $\beta A R-E R K$ pathway in adipocytes, such as the control of adipose-secreted factors as one example. Finally, the function of this $\beta$ AR-activated ERK pathway in brown adipocytes and the role of insulin in these effects has been partly investigated (Klein et al., 2000; Lindquist et al., 2000; Fasshauer et al., 2001) but much work remains to be done both mechanistically and in physiological terms to understand their roles and impact.

In addition to ERK, other MAPK kinases are also activated in response to $\beta A R s$ in adipocytes. p38 MAPK is activated by $\beta$ ARs in white (Moule and Denton, 1998; Mizuno et al., 2002) and brown adipocytes (Cao et al., 2001), including human adipocytes (Figure 4). As shown in Figure 5, we showed that p38 MAPK activation is indirectly dependent on PKA. An interesting aspect of $\beta A R-d e p e n d e n t$ activation of MAPKs in adipocytes is that JNK is not activated by $\beta$ ARs or cAMP (Robidoux et al., 2005). Important downstream targets of this pathway in brown adipocytes are the transcription of the Ucpl and PGC-1 $1 \alpha$ genes (Cao et al.,

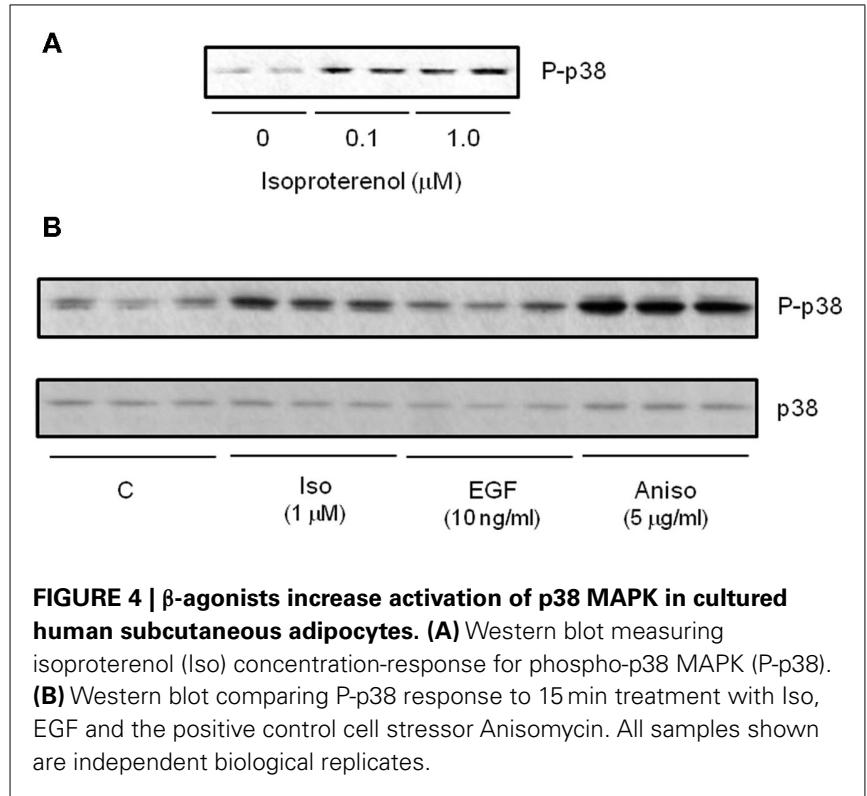

2001, 2004). Later work proposed p38 MAPK as one of the discriminating factors in the ability of certain mouse strains such as A/J to increase brown adipocyte numbers in WAT during early postnatal growth and development (Xue et al., 2006). p38 MAPK has also been implicated as a downstream factor in the reported permissive property of BMP7 to contribute to brown adipocyte differentiation (Tseng et al., 2008). If we think about how the three $\beta$ ARs activate the same pathways, it becomes clear that although the pathways are the same, the timing of the signaling is not necessarily identical, and signal strength can also be affected. For example, $\beta_{3} \mathrm{AR}$ sacrifices amplitude of cAMP generation to gain the ability to generate two signaling pathways simultaneously. These concepts are illustrated in Figure 6.

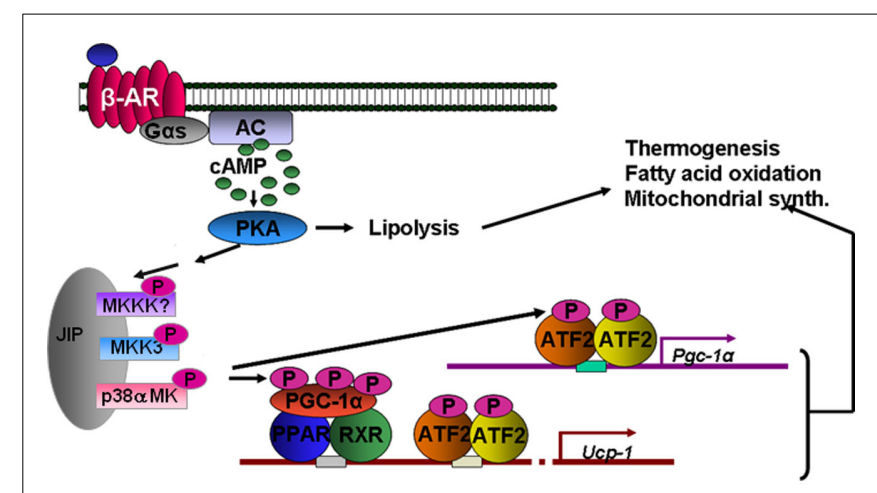

FIGURE 5 | $\beta$ AR activation of thermogenesis through p38 MAPK. Direct targets of p38 MAPK include peroxisome proliferator-activated receptor-gamma coactivator-1 $\alpha$ (PGC-1 $\alpha$ ) and ATF-2. These target the genes for $P g c-1 \alpha$ and $U_{c p} 1$. The tandem arrows between PKA and the MAPK module are not yet biochemically defined.

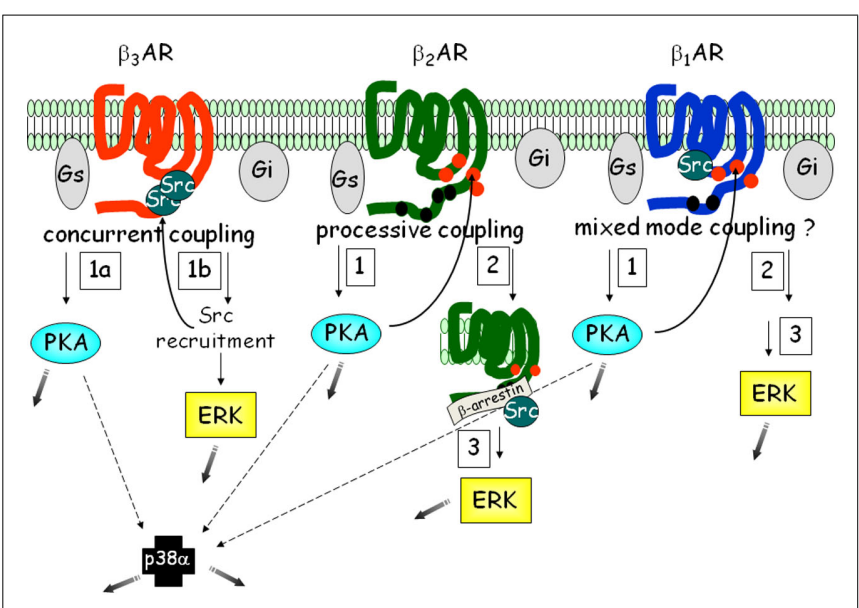

FIGURE 6 | Signaling networks of the $\beta$ ARs in adipocytes. Each of the three $\beta A R s$ is able to activate similar pathways: PKA, ERK, and p38 MAPK. However the order and number of steps involved varies, such that $\beta_{3} A R$ represents what we term "concurrent" coupling to Gs vs. Gi, vs. the $\beta_{2} A R$ type of "processive" coupling. Less is known about the details of $\beta_{1} A R$. Because $\beta_{1} A R$ also contains one of the PXXP motifs as in $\beta_{3} A R$, but it is also phosphorylated, we have provisionally termed in "mixed-mode" coupling. The shaded gray arrows point to subsequent downstream cellular effects. 
Mechanistically, the signaling components between PKA and p38 MAPK are not understood, although we have made some progress toward this goal. It appears that $\mathrm{p} 38 \alpha \mathrm{MAPK}$, but not p38 $\beta$ MAPK, is activated in brown adipocytes downstream of $\beta A R s$ and PKA, and that the immediate upstream kinase appears to specifically be MKK3 (Robidoux et al., 2005). In addition, although this $\beta \mathrm{AR} \rightarrow \mathrm{PKA} \rightarrow$ p38 MAPK pathway also exists in white adipocytes (including human adipocytes) the downstream functional consequences are as yet unknown. We generated mice with adipose-specific deletion of p38 $\alpha$ to uncover the role of PKAdependent p38 $\alpha$ MAPK activation in white adipocytes. In the absence of $\mathrm{p} 38 \alpha$ in adipocytes, preliminary evidence suggests that JNK now becomes active, similar to observations made for some other tissue-specific deletions of p38 $\alpha$ MAPK (Hui et al., 2007; Perdiguero et al., 2007; Ventura et al., 2007; Wada et al., 2008). Inappropriate JNK activation that occurs in other metabolic tissues such as muscle, liver, and fat has been associated with insulin resistance (Vallerie et al., 2008). Therefore, the complete characterization of these mice will hopefully fill in these gaps in our understanding of the mechanism(s) and physiological interplay between p38 MAPK and JNK in adipocytes and the mechanisms of their control.

Within the last couple of years there has been increasing evidence that AMPK is activated in adipocytes in response to lipolytic stimuli such as BARs (Hutchinson et al., 2005; Koh et al., 2007; Mulligan et al., 2007; Gauthier et al., 2008; Omar et al., 2009). AMPK activation is not necessarily a result of direct involvement of PKA but appears to be more related to lipolysis itself and its effect in reducing the net ATP levels within adipocytes. These findings suggest that lipolysis results in the increase in cellular energy consumption and this is proposed to be due to the stimulation of energy consuming processes such as fatty acid re-esterification and even mitochondrial uncoupling (Gauthier et al., 2008; Yehuda-Shnaidman et al., 2010).

\section{UNCOVERING PATHWAYS THAT SILENCE OR REPRESS ENERGY EXPENDITURE IN BROWN ADIPOCYTES}

We spend much effort trying to understand how to "stimulate" or "activate" and "turn on" catabolic pathways such as adaptive thermogenesis in brown adipocytes. However, if there are active mechanisms of repression, we need to identify them in order to

\section{REFERENCES}

Arch, J. R. (2002). beta(3)Adrenoceptor agonists: potential, pitfalls and progress. Eur. J. Pharmacol. 440, 99-107.

Arch, J. R. S., Ainsworth, A. T., Ellis, R. D., Piercy, V., Thody, V. E., Thurlby, P. L., Wilson, C., Wilson, S., and Young, P. (1984). Treatment of obesity with thermogenic $\beta$-adrenoceptor agonists: studies on BRL 28630A in rodents. Int. J. Obes. 8, $1-11$.

Bachman, E. S., Dhillon, H., Zhang, C. Y., Cinti, S., Bianco, A. C.,

release the "brake." Certain targeted gene disruptions in mice that result in a lean phenotype have provided some clues to such repressive pathways. Some of these genes include p70 S6 kinase (Um et al., 2004), estrogen related receptor- $\alpha$ (Luo et al., 2003), co-repressor RIP140 (Leonardsson et al., 2004), the liver X receptors (LXR; Kalaany et al., 2005), and others (Dong et al., 2009; Gao et al., 2009). Although the connections that may exist between these factors are not clear, mechanistically we have uncovered an interesting role at least for the nuclear factors LXR $\alpha$ and RIP140 to function as a regulated repressor complex that blocks $\beta$ AR-stimulated $U c p 1$ gene expression (Wang et al., 2008; Collins et al., 2010). Specifically, $\mathrm{LXR} \alpha$ recruits the co-repressor RIP140 to a DR-4 element in the $U c p 1$ enhancer adjacent to the PPAR/RXR binding DR-1 motif, leading to suppression of $U c p 1$ gene transcription. Given the common target and interaction between LXR and RIP140, we can link the phenotype of these individual mutations to a common mechanism. A necessary element for this repression by LXR $\alpha$ appears to be the availability of an LXR ligand. While the nature of these ligands and the enzymes that control their production are still a matter of much debate (Russell, 2000), at least one suggested candidate, cholesterol-25-hydroxylase, is expressed in white adipocytes at a level 30 times higher than in brown adipocytes (Wang et al., 2008). Therefore, this potential point of control will be an important feature to further explore. Since the ability to expand these reservoirs of "novel" brown adipocytes in vivo, to mobilize fuel and to activate thermogenesis all depend on the catecholamine stimulation of $\beta A R s$, our understanding of the signaling mechanisms of these receptors, and how they themselves are regulated, will be a key factor in harnessing the capacity for increasing these "plastic" brown adipocytes.

\section{CONCLUSION}

Although much is known about the signal transduction mechanism of $\beta$ ARs, the future ahead is still full of work to be done. Undoubtedly more surprises will be in store for us as we continue to uncover the signaling networks that $\beta$ ARs control in adipocytes and how we might be able to take advantage of this new knowledge to therapeutically intervene in combating the epidemic of metabolic disease in our midst.

\section{ACKNOWLEDGMENTS}

We thank Dr. Cynthia Nagle for Figure 5.

lipid droplets and control of lipolysis. J. Lipid Res. 48, 2547-2559.

Brasaemle, D. L., Dolios, G., Shapiro, L., and Wang, R. (2004). Proteomic analysis of proteins associated with lipid droplets of basal and lipolytically stimulated 3T3-L1 adipocytes. J. Biol. Chem. 279, 46835-46842.

Buemann, B., Toubro, S., and Astrup, A. (2000). Effects of the two beta3agonists, ZD7114 and ZD2079 on 24 hour energy expenditure and respiratory quotient in obese subjects. Int. J. Obes. Relat. Metab. Disord. 24, 1553-1560.
Cao, W., Daniel, K. W., Robidoux, J., Puigserver, P., Medvedev, A. V., Bai, X., Floering, L. M., Spiegelman, B. M., and Collins, S. (2004). p38 MAP kinase is the central regulator of cAMP-dependent transcription of the brown fat uncoupling protein-1 gene. Mol. Cell. Biol. 24, 3057-3067.

Cao, W., Luttrell, L. M., Medvedev, A. V., Pierce, K. L., Daniel, K. W., Dixon, T. M., Lefkowitz, R. J., and Collins, S. (2000). Direct binding of activated $\mathrm{c}$-Src to the $\beta 3$-adrenergic receptor is required for MAP kinase activation. J. Biol. Chem. 275, 38131-38134. 
Cao, W., Medvedev, A. V., Daniel, K. W., and Collins, S. (2001). $\beta$-Adrenergic activation of p38 MAP kinase in adipocytes: cAMP induction of the uncoupling protein-1 (UCP1) gene requires p38 MAP kinase. J. Biol. Chem. 276, 27077-27082.

Champigny, O., Ricquier, D., Blondel, O., Mayers, R. M., Briscoe, M. G., and Holloway, B. R. (1991). Beta 3-adrenergic receptor stimulation restores message and expression of brown-fat mitochondrial uncoupling protein in adult dogs. Proc. Natl. Acad. Sci. U.S.A. 88, 10774-10777.

Cinti, S. (1999). The Adipose Organ. Milano: Editrice Kurtis.

Cinti, S. (2005). The adipose organ. Prostaglandins Leukot. Essent. Fatty Acids 73, 9-15.

Collins, S., Cao, W., and Robidoux, J. (2004). Learning new tricks from old dogs: beta-adrenergic receptors teach new lessons on firing up adipose tissue metabolism. Mol. Endocrinol. 18, 2123-2131.

Collins, S., Daniel, K. W., Petro, A. E., and Surwit, R. S. (1997). Strainspecific response to $\beta 3$-adrenergic receptor agonist treatment of dietinduced obesity in mice. Endocrinology 138, 405-413.

Collins, S., Yehuda-Shnaidman, E., and Wang, H. (2010). Positive and negative control of Ucp1 gene transcription and the role of beta-adrenergic signaling networks. Int. J. Obes. (Lond.) 34(Suppl. 1), S28-S33.

Corbin, J. D., Keely, S. L., Soderling, T. R., and Park, C. R. (1975). Hormonal regulation of adenosine $3^{\prime}, 5^{\prime}$ monophosphate-dependent protein kinase. Adv. Cyclic Nucleotide Res. 5 , 265-279.

Cousin, B., Cinti, S., Morroni, M., Raimbault, S., Ricquier, D., Pénicaud, L., and Casteilla, L. (1992). Occurrence of brown adipocytes in rat white adipose tissue: molecular and morphological characterization. J. Cell. Sci. 103, 931-942.

Daub, H., Weiss, F. U., Wallasch, C., and Ullrich, A. (1996). Role of transactivation of the EGF receptor in signalling by G-protein-coupled receptors. Nature 379, 557-560.

De Matteis, R., Ricquier, D., and Cinti, S. (1998). TH-, NPY-, SP-, and CGRP-immunoreactive nerves in interscapular brown adipose tissue of adult rats acclimated at different temperatures: an immunohistochemical study. J. Neurocytol. 27, 877-886.

Dong, B., Saha, P. K., Huang, W., Chen, W., Abu-Elheiga, L. A., Wakil, S. J., Stevens, R. D., Ilkayeva, O., Newgard,
C. B., Chan, L., and Moore, D. D. (2009). Activation of nuclear receptor CAR ameliorates diabetes and fatty liver disease. Proc. Natl. Acad. Sci. U.S.A. 106, 18831-18836.

Fasshauer, M., Klein, J., Kriauciunas, K. M., Ueki, K., Benito, M., and Kahn, C. R. (2001). Essential role of insulin receptor substrate 1 in differentiation of brown adipocytes. Mol. Cell. Biol. 21, 319-329.

Fisher, M. H., Amend, A. M., Bach, T. J., Barker, J. M., Brady, E. J., Candelore, M. R., Carroll, D., Cascieri, M. A., Chiu, S. H., Deng, L., Forrest, M. J., Hegarty-Friscino, B., Guan, X. M., Hom, G. J., Hutchins, J. E. Kelly, L. J., Mathvink, R. J., Metzger, J. M., Miller, R. R., Ok, H. O., Parmee, E. R., Saperstein, R., Strader, C. D., Stearns, R. A., and MacIntyre, D. E. (1998). A selective human beta3 adrenergic receptor agonist increases metabolic rate in rhesus monkeys. J. Clin. Invest. 101, 2387-2393.

Franke, W. W., Hergt, M., and Grund, C. (1987). Rearrangement of the vimentin cytoskeleton during adipose conversion: formation of an intermediate filament cage around lipid globules. Cell 49, 131-141.

Gao, J., He, J., Zhai, Y., Wada, T., and Xie, W. (2009). The constitutive androstane receptor is an anti-obesity nuclear receptor that improves insulin sensitivity. J. Biol. Chem. 284, 25984-25992.

Garofalo, M. A., Kettelhut, I. C., Roselino, J. E., and Migliorini, R. H. (1996). Effect of acute cold exposure on norepinephrine turnover rates in rat white adipose tissue. J. Auton. Nerv. Syst. 60. 206-208.

Gauthier, M. S., Miyoshi, H., Souza, S. C., Cacicedo, J. M., Saha, A. K., Greenberg, A. S., and Ruderman, N. B. (2008). AMP-activated protein kinase is activated as a consequence of lipolysis in the adipocyte: potential mechanism and physiological relevance. J. Biol. Chem. 283, 16514-16524.

Giordano, A., Morroni, M., Santone, G., Marchesi, G. F., and Cinti, S. (1996). Tyrosine hydroxylase, neuropeptide $\mathrm{Y}$, substance $\mathrm{P}$, calcitonin gene-related peptide and vasoactive intestinal peptide in nerves of rat periovarian adipose tissue: an immunohistochemical and ultrastructural investigation. J. Neurocytol. 25, 125-136.

Greenberg, A. S., Shen, W. J., Muliro, K., Patel, S., Souza, S. C., Roth, R. A., and Kraemer, F. B. (2001). Stimulation of lipolysis and hormonesensitive lipase via the extracellular signal-regulated kinase pathway. $J$. Biol. Chem. 276, 45456-45461.

Himms-Hagen, J., Cui, J., Danforth, E. Jr., Taatjes, D. J., Lang, S. S. Waters, B. L., and Claus, T. H. (1994). Effect of CL-316,243, a thermogenic $\beta 3$-agonist, on energy balance and brown and white adipose tissues in rats. Am. J. Physiol. 266, R1371R1382.

Hui, L., Bakiri, L., Mairhorfer, A. Schweifer, N., Haslinger, C., Kenner, L., Komnenovic, V., Scheuch, H. Beug, H., and Wagner, E. F. (2007) p38alpha suppresses normal and cancer cell proliferation by antagonizing the JNK-c-Jun pathway. Nat. Genet. 39, 741-749.

Hutchinson, D. S., Chernogubova, E., Dallner, O. S., Cannon, B., and Bengtsson, T. (2005). Beta-adrenoceptors, but not alpha-adrenoceptors, stimulate AMP-activated protein kinase in brown adipocytes independently of uncoupling protein-1. Diabetologia 48, 2386-2395.

Jimenez, M., Léger, B., Canola, K., Lehr, L., Arboit, P., Seydoux, J., Russell, A. P., Giacobino, J. P., Muzzin, P., and Preitner, F (2002). Beta(1)/beta(2)/beta(3)adrenoceptor knockout mice are obese and cold-sensitive but have normal lipolytic responses to fasting. FEBS Lett. 530, 37-40.

Kalaany, N. Y., Gauthier, K. C., Zavacki, A. M., Mammen, P. P., Kitazume, T., Peterson, J. A., Horton, J. D., Garry, D. J., Bianco, A. C., and Mangelsdorf, D. J. (2005). LXRs regulate the balance between fat storage and oxidation. Cell Metab. 1, 231-244.

Klein, J., Fasshauer, M., Benito, M., and Kahn, C. R. (2000). Insulin and the beta3-adrenoceptor differentially regulate uncoupling protein1 expression. Mol. Endocrinol. 14, 764-773.

Koh, H. J., Hirshman, M. F., He, H., Li, Y., Manabe, Y., Balschi, J. A., and Goodyear, L. J. (2007) Adrenaline is a critical mediator of acute exercise-induced AMPactivated protein kinase activation in adipocytes. Biochem. J. 403, 473-481.

Kortelainen, M.-L., Pelletier, G., Ricquier, D., and Bukowiecki, L. J. (1993). Immunohistochemical detection of human brown adipose tissue uncoupling protein in an autopsy series. J. Histochem. Cytochem. 41, 759-764.

Kumar, N., Robidoux, J., Daniel, K. W., Guzman, G., Floering, L. M., and Collins, S. (2007). Requirement of vimentin filament assembly for beta3-adrenergic receptor activation of ERK MAP kinase and lipolysis. $J$. Biol. Chem. 282, 9244-9250.

Lass, A., Zimmermann, R., Oberer, M., and Zechner, R. (2011). Lipolysis - a highly regulated multi-enzyme complex mediates the catabolism of cellular fat stores. Prog. Lipid Res. 50, 14-27.

Lean, M. E. J. (1989). Brown adipose tissue in humans. Proc. Nutr. Soc. 48 , 243-256.

Lefkowitz, R. J., Rajagopal, K., and Whalen, E. J. (2006). New roles for beta-arrestins in cell signaling: not just for seven-transmembrane receptors. Mol. Cell 24, 643-652.

Leonardsson, G., Steel, J. H., Christian, M., Pocock, V., Milligan, S., Bell, J., So, P. W., Medina-Gomez, G., VidalPuig, A., White, R., and Parker, M. G. (2004). Nuclear receptor corepressor RIP140 regulates fat accumulation. Proc. Natl. Acad. Sci. U.S.A. 101, 8437-8442.

Liggett, S., Freedman, N. J., Schwinn, D. A., and Lefkowitz, R. J. (1993). Structural basis for receptor subtypespecific regulation revealed by a chimeric $\beta 3$-/ $\beta 2$-adrenergic receptor. Proc. Natl. Acad. Sci. U.S.A. 90, 3665-3669.

Lindquist, J. M., Fredriksson, J. M., Rehnmark, S., Cannon, B., and Nedergaard, J. (2000). beta 3- and alpha 1-adrenergic Erk1/2 activation is Src- but not Gi-mediated in brown adipocytes. J. Biol. Chem. 275, 22670-22677.

Lohse, M., Benovic, J. L., Codina, J., Caron, M. G., and Lefkowitz, R. J. (1990). $\beta$-arrestin: a protein that regulates $\beta$ adrenergic receptor function. Science 248, 1547-1550.

Luo, J., Sladek, R., Carrier, J., Bader, J. A., Richard, D., and Giguère, V. (2003). Reduced fat mass in mice lacking orphan nuclear receptor estrogenrelated receptor alpha. Mol. Cell. Biol. 23, 7947-7956.

Luttrell, L. (2003). 'Location, location, location': activation and targeting of MAP kinases by $\mathrm{G}$ protein-coupled receptors. J. Mol. Endocrinol. 30, 117-126.

Luttrell, L. M., Ferguson, S. S., Daaka, Y., Miller, W. E., Maudsley, S., Della Rocca, G. J., Lin, F., Kawakatsu, H., Owada, K., Luttrell, D. K., Caron, M. G., and Lefkowitz, R. J. (1999). Beta-arrestin-dependent formation of beta2 adrenergic receptor-Src protein kinase complexes. Science 283, 655-661.

Martin, N. P., Whalen, E. J., Zamah, M. A., Pierce, K. L., and Lefkowitz, R. J. (2004). PKAmediated phosphorylation of the 
betal-adrenergic receptor promotes Gs/Gi switching. Cell. Signal. 16, 1397-1403.

McConnachie, G., Langeberg, L. K., and Scott, J. D. (2006). AKAP signaling complexes: getting to the heart of the matter. Trends Mol. Med. 12, 317-323.

Mizuno, K., Kanda, Y., Kuroki, Y., Nishio, M., and Watanabe, Y. (2002). Stimulation of beta(3)-adrenoceptors causes phosphorylation of p38 mitogen-activated protein kinase via a stimulatory $\mathrm{G}$ protein-dependent pathway in 3T3-L1 adipocytes. Br. J. Pharmacol. 135, 951-960.

Moule, S. K., and Denton, R. M. (1998). The activation of p38 MAPK by the beta-adrenergic agonist isoproterenol in rat epididymal fat cells. FEBS Lett. 439, 287-290.

Mulligan, J. D., Gonzalez, A. A., Stewart, A. M., Carey, H. V., and Saupe, K. W. (2007). Upregulation of AMPK during cold exposure occurs via distinct mechanisms in brown and white adipose tissue of the mouse. J. Physiol. (Lond.) 580, 677-684.

Nedergaard, J., Golozoubova, V., Matthias, A., Asadi, A., Jacobsson, A., and Cannon, B. (2001). UCP1: the only protein able to mediate adaptive non-shivering thermogenesis and metabolic inefficiency. Biochim. Biophys. Acta 1504, 82-106.

Omar, B., Zmuda-Trzebiatowska, E., Manganiello, V., Göransson, O., and Degerman, E. (2009). Regulation of AMP-activated protein kinase by cAMP in adipocytes: roles for phosphodiesterases, protein kinase B, protein kinase A, Epac and lipolysis. Cell. Signal. 21, 760-766.

Perdiguero, E., Ruiz-Bonilla, V., Gresh, L., Hui, L., Ballestar, E., SousaVictor, P., Baeza-Raja, B., Jardí, M., Bosch-Comas, A., Esteller, M., Caelles, C., Serrano, A. L., Wagner, E. F., and Muñoz-Cánoves, P. (2007). Genetic analysis of p38 MAP kinases in myogenesis: fundamental role of p38alpha in abrogating myoblast proliferation. $E M B O \mathrm{~J} .26$, 1245-1256.

Pidoux, G., Witczak, O., Jarnæss, E., Myrvold, L., Urlaub, H., Stokka, A. J., Küntziger, T., and Taskén, K. (2011). Optic atrophy 1 is an Akinase anchoring protein on lipid droplets that mediates adrenergic control of lipolysis. EMBO J. 30, 3271-3286.

Reiter, E., and Lefkowitz, R. J. (2006). GRKs and beta-arrestins: roles in receptor silencing, trafficking and signaling. Trends Endocrinol. Metab. 17, 159-165.

Robidoux, J., Cao, W., Quan, H., Daniel, K. W., Moukdar, F., Bai, X., Floering, L. M., and Collins, S. (2005). Selective activation of mitogen-activated protein (MAP) kinase kinase 3 and p38\{alpha\} MAP kinase is essential for cyclic AMP-dependent UCP1 expression in adipocytes. Mol. Cell. Biol. 25, 5466-5479.

Robidoux, J., Kumar, N., Daniel, K. W., Moukdar, F., Cyr, M., Medvedev, A. V., and Collins, S. (2006). Maximal beta3-adrenergic regulation of lipolysis involves $\mathrm{Src}$ and epidermal growth factor receptor-dependent ERK1/2 activation. J. Biol. Chem. 281, 37794-37802.

Russell, D. W. (2000). Oxysterol biosynthetic enzymes. Biochim. Biophys. Acta 1529, 126-135.

Soeder, K. S., Snedden, S. K., Cao, W., Della Rocca, G. J., Daniel, K. W., Luttrell, L. M., and Collins, S. (1999). The $\beta 3$-adrenergic receptor activates mitogen-activated protein kinase in adipocytes through a Gi-dependent mechanism. J. Biol. Chem. 274, 12017-12022.

Thomas, S. A., and Palmiter, R. D. (1997). Thermoregulatory and metabolic phenotypes of mice lacking noradrenaline and adrenaline. Nature 397, 94-97.
Tseng, Y. H., Kokkotou, E., Schulz, T. J., Huang, T. L., Winnay, J. N., Taniguchi, C. M., Tran, T. T., Suzuki, R., Espinoza, D. O., Yamamoto, Y., Ahrens, M. J., Dudley, A. T., Norris, A. W., Kulkarni, R. N., and Kahn, C. R. (2008). New role of bone morphogenetic protein 7 in brown adipogenesis and energy expenditure. Nature 454, 1000-1004.

Um, S. H., Frigerio, F., Watanabe, M. Picard, F., Joaquin, M., Sticker, M. Fumagalli, S., Allegrini, P. R., Kozma, S. C., Auwerx, J., and Thomas, G. (2004). Absence of S6K1 protects against age- and diet-induced obesity while enhancing insulin sensitivity. Nature 431, 200-205.

Vallerie, S. N., Furuhashi, M., Fucho, R., and Hotamisligil, G. S. (2008) A predominant role for parenchymal c-Jun amino terminal kinase (JNK) in the regulation of systemic insulin sensitivity. PLOS ONE 3, e3151. doi:10.1371/journal.pone.0003151

van Biesen, T., Luttrell, L. M., Hawes, B. E., and Lefkowitz, R. J. (1996). Mitogenic signaling via $G$ proteincoupled receptors. Endocr. Rev. 17, 698-714.

Ventura, J. J., Tenbaum, S., Perdiguero, E., Huth, M., Guerra, C., Barbacid M., Pasparakis, M., and Nebreda, A. R. (2007). p38alpha MAP kinase is essential in lung stem and progenitor cell proliferation and differentiation. Nat. Genet. 39, 750-758.

Wada, T., Stepniak, E., Hui, L., Leibbrandt, A., Katada, T., Nishina, H., Wagner, E. F., and Penninger, J. M. (2008). Antagonistic control of cell fates by JNK and p38-MAPK signaling. Cell Death Differ. 15 , 89-93.

Wang, H., Zhang, Y., YehudaShnaidman, E., Medvedev, A. V., Kumar, N., Daniel, K. W., Robidoux, J., Czech, M. P., Mangelsdorf, D. J., and Collins, S. (2008). Liver X receptor is a transcriptional repressor of the uncoupling protein-1 gene and brown adipocyte phenotype. Mol. Cell. Biol. 28, 2187-2200.

Xue, B., Rim, J. S., Hogan, J. C., Coulter, A. A., Koza, R. A., and Kozak, L. P. (2006). Genetic variability affects the development of brown adipocytes in white fat, but not in interscapular brown fat. J. Lipid Res. 48, 41-51.

Yehuda-Shnaidman, E., Buehrer, B., Pi, J., Kumar, N., and Collins, S. (2010). Acute stimulation of white adipocyte respiration by PKA-induced lipolysis. Diabetes 59, 2474-2483.

Zamah, A. M., Delahunty, M., Luttrell, L. M., and Lefkowitz, R. J. (2002). Protein kinase A-mediated phosphorylation of the beta 2-adrenergic receptor regulates its coupling to Gs and Gi. Demonstration in a reconstituted system. J. Biol. Chem. 277, 31249-31256.

Conflict of Interest Statement: The author declares that the research was conducted in the absence of any commercial or financial relationships that could be construed as a potential conflict of interest.

Received: 05 October 2011; paper pending published: 20 November 2011; accepted: 02 December 2011; published online: 03 January 2012.

Citation: Collins $S$ (2012) $\beta$ Adrenoceptor signaling networks in adipocytes for recruiting stored fat and energy expenditure. Front. Endocrin. 2:102. doi: 10.3389/fendo.2011.00102 This article was submitted to Frontiers in Cellular Endocrinology, a specialty of Frontiers in Endocrinology.

Copyright (C) 2012 Collins. This is an open-access article distributed under the terms of the Creative Commons Attribution Non Commercial License, which permits non-commercial use, distribution, and reproduction in other forums, provided the original authors and source are credited. 